\title{
3D PRINTING AND FUNCTIONALIZATION OF TEXTILES
}

\author{
Marjeta Čuk (D), Matejka Bizjak (D), Deja Muck (D), Tanja Nuša Kočevar (i) \\ University of Ljubljana, Faculty of Natural Sciences and Engineering, \\ Department of Textiles, Graphic Arts and Design, Ljubljana, Slovenia
}

\begin{abstract}
D$ printing is used to produce individual objects or to print on different substrates to produce multi-component products. In the textile industry, we encounter various $3 D$ printing technologies in fashion design, functional apparel manufacturing (protective, military, sports, etc.), including wearable electronics, where textile material is functionalized. 3D printing enables the personalization of the product, which in the apparel industry can be transformed into the production of clothing or parts of clothing or custom accessories.

Additive technology allows a more rational use of the material than traditional technologies. In the textile industry we meet different uses of it, one is the printing of flexible structures based on rigid materials, another is the printing with flexible materials and the third is the printing directly on textile substrate. All rigid, hard and soft or flexible materials can be integrated into the final design using 3D printing directly on the textile substrate. We speak of so-called multi-material objects and systems, which have many advantages, mainly in the increasing customization and functionalization of textiles or clothing.

The article gives a broader overview of 3D printing on textiles and focuses mainly on the influence of different parameters of printing and woven fabric properties on the adhesion of 3D printed objects on the textile substrate.

In our research we investigated the influence of twill weave and its derivate as well as different weft densities of the woven fabric on the adhesion of printed objects on textile substrate. Therefore, five samples of twill polyester/cotton fabrics were woven and their physical properties measured for this research. 3D objects were printed on textile substrates using the extrusion based additive manufacturing technique with polylactic acid (PLA) filament. Preliminary tests were carried out to define printing parameters and different methods of attaching the fabric to a printing bed were tested. $T$ - Peel adhesion tests were performed on the Instron dynamometer to measure the adhesion between $3 D$ printed objects and textile substrates.
\end{abstract}

Key words: 3D printing, FDM, textiles, woven structure, multi-material object

\section{INTRODUCTION}

3D printing technology has developed very rapidly over the last years and is used in various fields of industry. It is an additive manufacturing (AM) technology based on the principle of building objects by adding layers of material and connecting them in different ways depending on the type of 3D technology and the material used (Gibson et al, 2015).

Only recently 3D printing became established in the fashion and textile industry where various technologies are used for production of decorative elements, fashion accessories, various textile structures or for functionalization of textile. For example, the fashion industry uses 3D technology for innovative products such as 3D printed shoes, garments, accessories, designed by many prominent designers.

As Sitotaw and colleagues (Sitotaw et al, 2020) consider the present state of textiles and additive manufacturing, the new technology in general influences the textile production in three directions: One is printing of flexible structures based on rigid materials, where structures are made to recreate some textile properties. Designers and technologists are exploiting many possibilities of the shape complexity of 3D models and the use of material properties to create 3D printed textile-based structures. For example, Melnikova and associates used Selective laser sintering (SLS) and Fused Deposition Modeling (FDM) technology to create weft knitted fabric structures (Melnikova et al, 2014).

Another direction that is emphasized is printing with flexible materials. The third direction is 3D printing on textiles, which is the most used process at the moment. It is utilized for adding different features and functions to the textile that can make a product that is personalized and optionally customized. Different polymers can be printed directly onto textile surfaces in previously modeled forms to produce multimaterial objects that combine the advantages of both technologies and materials (Unger et al, 2018), (Kozior et al, 2018). Creating multi material objects with 3D printing on textile substrate, aesthetics and 
functionality can be added to textile fabrics by improving the mechanical properties of the fabrics and maintaining their drape and other characteristics.

Fused Deposition Modeling (FDM) technology is the most appropriate for printing on existing objects (Kozior et al, 2018), therefore it is usually used for production of multi-material objects with textiles. FDM is the AM technology based on material extrusion in which a preheating station raises the temperature of the material, which is a polymer, to the melting point so that it can flow through a feed system. The polymer is fed into the system in the form of a thread. (Gibson et al, 2015)

Polymers frequently used for 3D printing with FDM technology are polylactic acid (PLA), that is the most commonly used material, acrylonitrile butadiene styrene (ABS), and some other materials, such as polycarbonate (PC), blend of PC and ABS and others (Muck et al, 2015). Regarding polymers commonly used for 3D printing, some researches have shown that printing with ABS produces lower adhesion than with PLA (Rivera et al, 2017; Pei et al, 2015), which may be the result of a higher viscosity of the latter during the 3D printing process (Kozior et al, 2020). The most important properties of multi-material objects made of 3D printed layers on textile substrates are good adhesion while maintaining the flexibility of the fabric. Particularly good adhesion is a very important factor because it influences the quality and durability of the final product. Nevertheless, flexibility is also of great importance.

The adhesion of the polymer to the substrate is performed by three main adhesion mechanisms that are mechanical coupling, molecular bonding and thermodynamic adhesion (Awaya et al, 2009).

A lot of research was performed on adhesion of 3D printed material on textile substrates (Pei et al, 2015), (Sanatgar et al, 2017) where different parameters were investigated, such as: fabric chemical pretreatment, weave pattern and infill orientation (Kozior et al, 2018), changes in shape geometry of printed materials (Spahiu et al, 2019), changes in structural properties of the fabric, changes of textile material (Mpofu et al, 2019; Sabantina et al, 2015; Malengier et al, 2017), and so on.

One of the very important printing parameters that influences the adhesion on textile substrates is the distance between the nozzle and the printing bed. If we reduce the distance, the adhesion force increases until the minimum distance is reached and the filament does not clog the nozzle. At a smaller distance the nozzle presses the polymer into the pore of the fabric with higher force (Spahiu et al, 2018). The temperature of the printing bed and nozzle has also great influence on the adhesion force, which was determined in various investigations. By increasing both temperatures, the viscosity of the molten PLA decreases during the printing process, which causes the material to penetrate deeper into the woven fabric (Spahiu et al, 2017; Spahiu et al 2018). In addition, the adhesion force depends on different infill orientations and also on the orientation of the first printing layer (Kozior et al, 2018).

The aim of our research was to investigate the influence of the fabric structure, namely weave and thread density, which have the greatest influence on the fabric surface. In addition to the fabric surface, which is crucial for adhesion in 3D printing on textiles, the mechanical properties of woven fabric are also important for many applications, including a composite that can be used for protective clothing. Therefore, twill weave was investigated, whereas it has very good mechanical properties and higher tensile strength compared to the plain weave (Jahan, 2017).

Twill weave and its derivative as well as different weft densities of the woven fabric were used to investigate the adhesion of printed products on fabric substrate.

\section{METHODS}

Five samples of polyester/cotton twill fabric were designed in ArahWeave program and woven for the purposes of this research. Two different weaves of four - end twill are shown as technical diagrams with their labels in Figure 1.
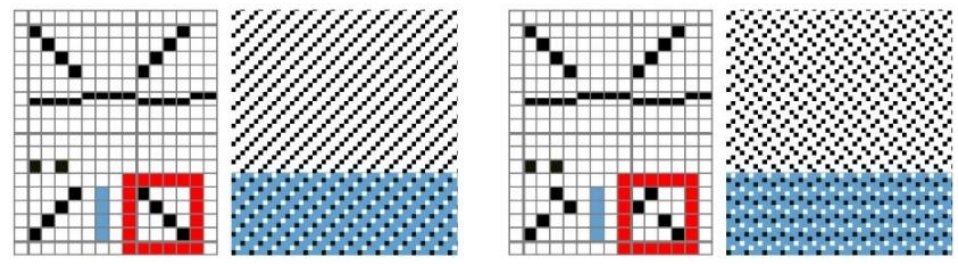

Figure 1: Technical schemes of woven fabrics and their labels (left: twill 1/3 - K13Z, right: broken twill 1/3 - K13L) 
All samples were woven on a Minifaber laboratory loom with a TIS jacquard mechanism with the preset warp density 40 ends/cm and three different weft densities: 15, 20 and 22 picks/cm. Black and white cotton yarns with a fineness of $8 \times 2$ tex were used for the warp and polyester blue yarn with a fineness of 33 tex for the weft.

Table 1 shows measured values of fabrics parameters. Physical properties such as yarn fineness, thickness, mass per square meter, real warp and weft density were measured in accordance with the standards. The thickness of the fabric was measured with a fabric thickness tester in two ways. Thickness 1 was measured according to the standard EN ISO 9863-1 with the standard circular pressure foot. Thickness 2 was measured when the fabric was placed in the mounting frame prepared for 3D printing and allowed a more accurate determination of the distance between the fabric and the nozzle. The mounting frame was designed so that the fabric could be placed on the 3D printer more accurately and quickly. The fabrics were raw and were not pretreated before 3D printing.

Table 1: Measured values of constructional properties of woven fabrics used as substrates for 3D printing (the sample label includes the name of the weave structure and the preset number of wefts per centimeter)

\begin{tabular}{|c|c|c|c|c|c|}
\hline Sample & $\begin{array}{c}\text { Thickness 1 } \\
(\mathrm{mm})\end{array}$ & $\begin{array}{c}\text { Thickness 2 } \\
(\mathrm{mm})\end{array}$ & $\begin{array}{c}\text { Mass } \\
\left(\mathrm{g} / \mathrm{m}^{2}\right)\end{array}$ & $\begin{array}{c}\text { Warp density } \\
(\mathrm{ends} / 10 \mathrm{~cm})\end{array}$ & $\begin{array}{c}\text { Weft density } \\
\text { (picks/10 cm) }\end{array}$ \\
\hline K13L 15 & 0.508 & 0.430 & 114.0 & 407 & 150 \\
\hline K13L 20 & 0.473 & 0.408 & 139.8 & 406 & 217 \\
\hline K13Z 15 & 0.489 & 0.423 & 112.8 & 404 & 146 \\
\hline K13Z 20 & 0.487 & 0.430 & 140.4 & 406 & 223 \\
\hline K13Z 22 & 0.474 & 0.424 & 152.6 & 415 & 252 \\
\hline
\end{tabular}

The 3D model of $25 \mathrm{~mm} \times 160 \mathrm{~mm} \times 0.4 \mathrm{~mm}$ was modeled, according to standard requirements, in the open source 3D creation suite Blender and exported as stl file. The stl file was imported into the slicing software Voxelizer, where all parameters for 3D printing were set (Table 2). The G-code was adjusted manually to avoid crashes of printing nozzle into the installation frame in which the fabrics were inserted. All the samples were printed with the ZMorph $2.0 \mathrm{SX} 3 \mathrm{D}$ printer with $1.75 \mathrm{~mm}$ PLA gray AzureFilm filament.

T - Peel adhesion tests were performed according to standard DIN 53530 using an Instron 5567 dynamometer, the separation rate was $100 \mathrm{~mm} / \mathrm{min}$.

Table 2: Printing parameters

\begin{tabular}{|l|c|}
\hline Parameter & Value \\
\hline Nozzle size & $0.4 \mathrm{~mm}$ \\
\hline Layer height & $0.2 \mathrm{~mm}$ \\
\hline Number of layers & 2 \\
\hline Infill print speed & $40 \mathrm{~mm} / \mathrm{s}$ \\
\hline Infill angle & $45^{\circ}$ \\
\hline Outline print speed & $30 \mathrm{~mm} / \mathrm{s}$ \\
\hline Outline count & 2 \\
\hline Extruder temperature & $210^{\circ} \mathrm{C}$ \\
\hline Bed temperature & $60^{\circ} \mathrm{C}$ \\
\hline Z-value (at first layer) & 0,35 \\
\hline
\end{tabular}

\section{RESULTS}

Figure 2 shows that in all cases, the measured warp density increased compared to the preset on-loom value, most pronounced for the fabric K13Z 22 by $3.75 \%$. The measured weft densities for the fabrics with the preset on-loom weft density 15 picks/cm stayed the same or decreased slightly, while the measured weft densities increased for the fabrics with 20 or 22 picks/cm preset weft density. The increase was highest for the sample K13Z 22 with 14.55\%.

With increasing weft density, the areal weight increased (Table 1), while the Thickness 1 and the Thickness 2 decreased. 


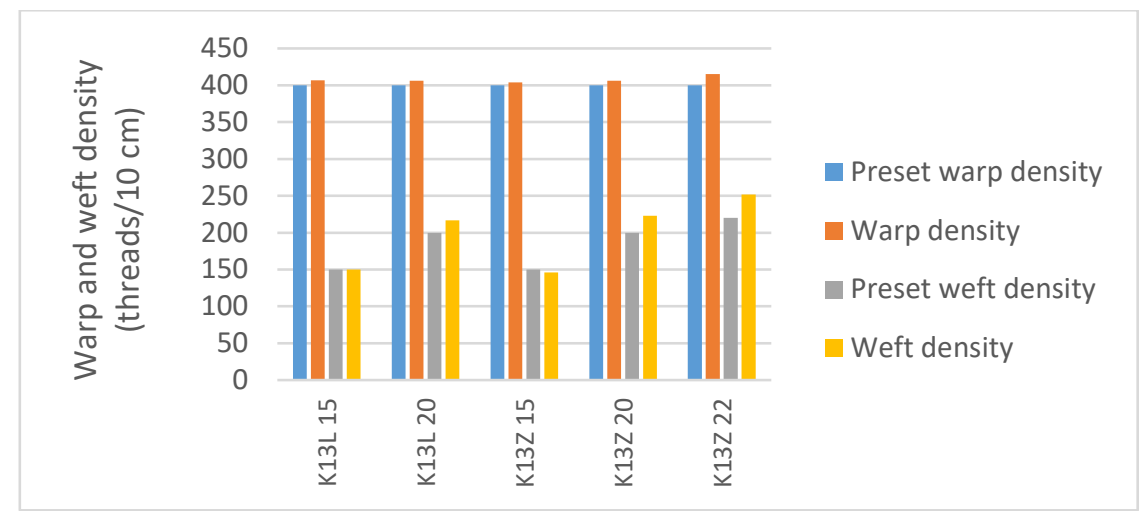

Figure 2: Preset and real densities of woven substrates

Figure 3 shows maximum adhesion forces and standard deviation on 3D printed textile substrates with the same weave and different weft densities. Stripped bars in the figures from 3 to 6 indicate that the fabric ruptured during adhesion test, before 3D printed object was detached from fabric.

The highest adhesion force was achieved at the lowest weft density at both weaves (K13Z and K13L) and the lowest adhesion force was achieved at preset weft density 20 picks $/ \mathrm{cm}$ and the broken twill $1 / 3$ (K13L). The highest standard deviation was calculated at broken twill $1 / 3$ and preset weft density 15 picks/cm (K13L 15) and the lowest at twill 1/3 and preset weft density 22 picks/cm (K13Z 22).

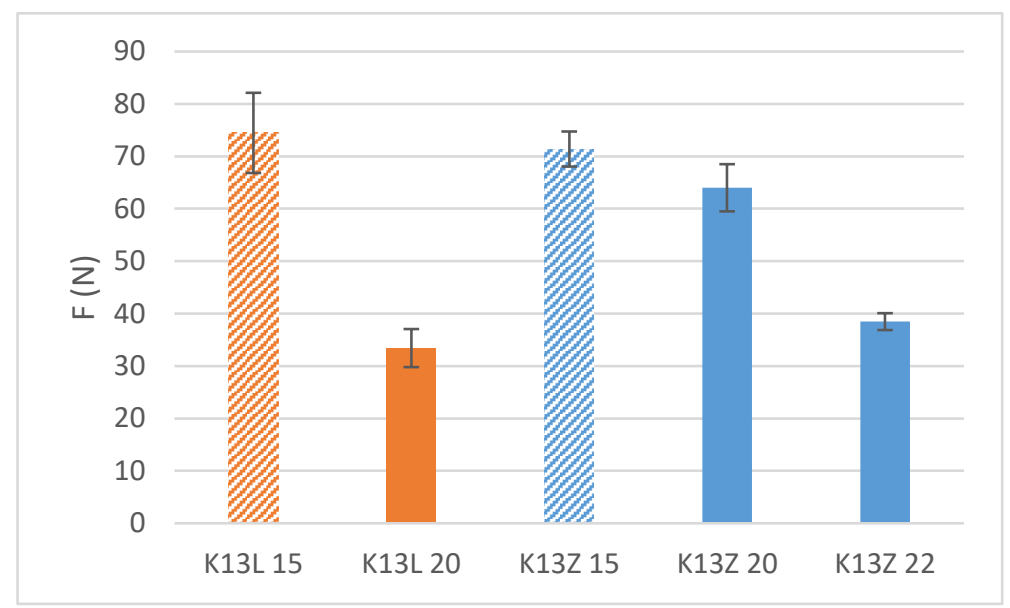

Figure 3: Dependence of the adhesion force on the woven samples

Comparing both weaves at the preset weft density 15 picks $/ \mathrm{cm}$, it can be seen that the highest adhesion forces are very similar for both samples (74,47 N for sample K13Z 15 and 71,39 N for sample K13L 15). The adhesion force on the twill $1 / 3$ is slightly lower than on the broken twill $1 / 3$. At the preset weft density of 20 picks $/ \mathrm{cm}$ the difference between the two adhesive forces is higher, the adhesion force on the twill $1 / 3$ is $64,01 \mathrm{~N}$ and on the broken twill $33,43 \mathrm{~N}$.

Figure 4 shows the influence of the mass on the adhesion force for different samples. For the same weave, the adhesion force decreases with increasing mass. Comparing all the samples, a change in the mass of the samples has no direct influence on the change in the adhesive force, but there is a general tendency that the adhesion force decreases with increasing mass. 


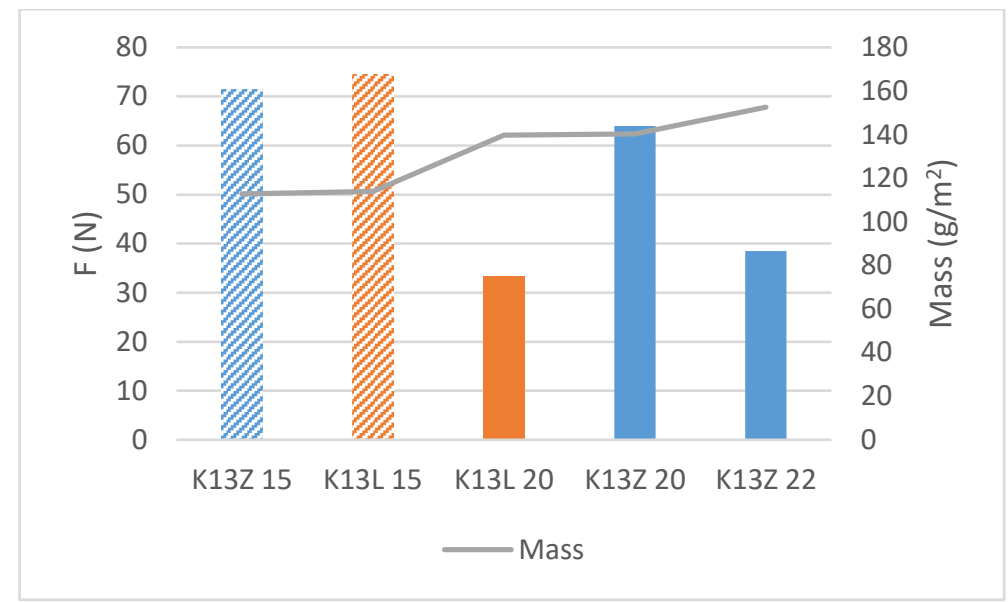

Figure 4: Dependence of the adhesion force on the mass for different samples

In Figure 5, where the dependence of the adhesion force on the thickness of the fabric, measured according to the textile standard on the samples, is shown that the adhesion force increases with increasing thickness.

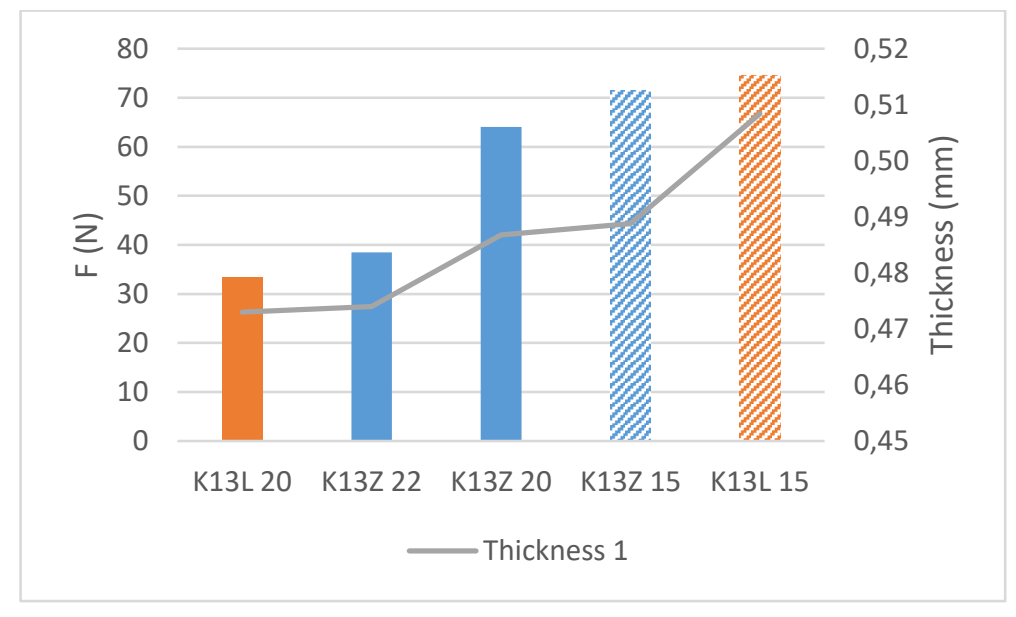

Figure 5: Dependence of the adhesion force on Thickness 1

Figure 6 shows the influence of the measured weft and warp densities on the adhesion force for different samples.

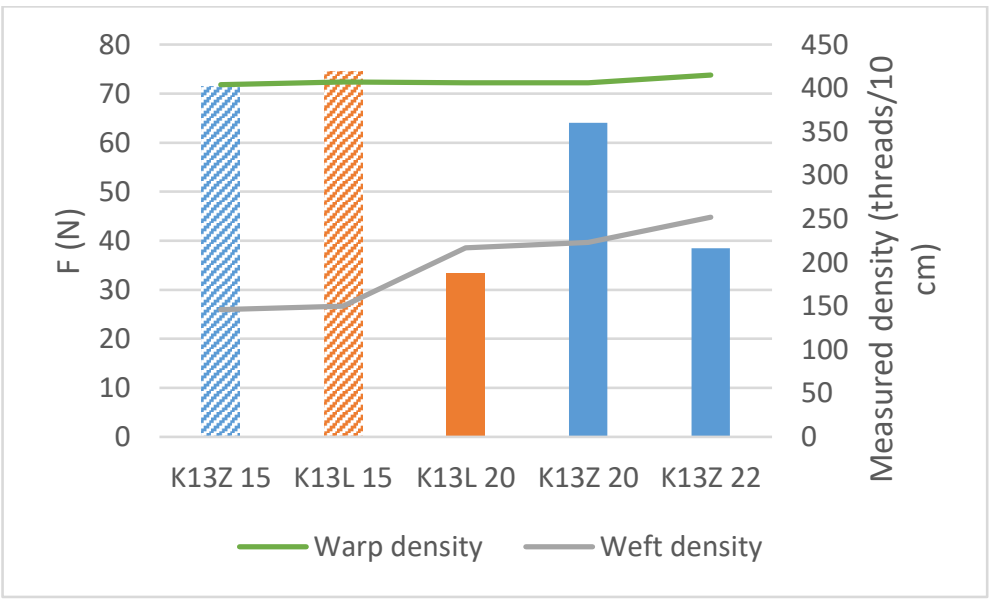

Figure 6: Dependence of the adhesion force on measured warp and weft densities 
The adhesion force decreases with increasing weft density for the same weave. Comparing all samples, the tendency is that the adhesion force decreases when the measured weft density increases, but the correlation is not direct. An increase in the measured warp density also shows a general, but not direct, tendency for the adhesion force to decrease.

\section{DISCUSSION}

In our research, we focused on the influence of the construction properties of fabrics on the adhesion of 3D printed objects on textile substrate. All textile samples were woven on the same cotton warp with the fineness $(8 \times 2$ tex) and density 40 ends/cm. The weft yarn remains the same for all samples (100\% PES, 33 tex). Three different weft densities $(15,20$ and 22 picks $/ \mathrm{cm})$ and two different weaves, namely twill $1 / 3$ and broken twill $1 / 3$, were used as textile components. 3D objects were printed with PLA on textile substrates. Preliminary tests were done to define the nozzle temperature, the $Z$ height of the nozzle and the printing angle of the first layer. The define the exact positioning of the fabric on the printing bed, different methods of attaching the fabric to a printing bed were tested.

The adhesion force was tested on all samples. The highest adhesion was found at the lowest weft density in both weaves, where the adhesion was slightly higher at broken twill $1 / 3$ than at twill $1 / 3$. The lowest adhesion was found at the highest weft density, which means that at larger pores, which is the case at low weft density, the polymer adheres more strongly to the substrate than vice versa. This can be explained by the fact that with the increasing density of the weft yarns, the polymer can hardly enclose the individual yarns. As a result, the polymer has less surface area available to adhere to the fabric, which reduces the adhesion force. The measured warp density differed only very little between the samples, but the increase in warp density also shows a general, but not direct tendency to decrease the adhesion force.

A change in the mass of the samples has no direct influence on the change in adhesive force, but there is a general tendency for the adhesion force to decrease with increasing mass. In our case, the increase in the mass of the fabric is directly related to the increase in the density of the warp and weft, so we assume that the cause of the change in adhesion force is the same as the change in the density of the warp and weft described above.

Results show that the adhesion force increases with increasing thickness. The fabric thickness measured according to the textile standard generally increases with decreasing weft density, which leads to longer floats of the warp threads and to larger available yarn surfaces for polymer adhesion.

In addition, during our research were obtained further important findings, which confirm earlier research in this field:

- The exact positioning of the fabric on the printing bed is very important, while the angles between the warp threads, the weft threads and the direction of the first printing layer must be as accurate as possible. This is why we have designed the frame for the precise attachment of the fabric to the printing bed. As described in the literature (T. Kozior et. al. 2018), the direction of the first printing layer is important. The results of our tests showed, as already indicated, that when the first layer is printed at an angle of 90 degrees to the longer size of the sample (warp direction), the adhesive force is the highest, while at 0 degrees the force is the lowest. Since the samples with first layer printed at 90 degrees, tear too quickly during the peel test, we printed the first layer at 45 degrees according to the longer size.

- The thickness of the fabric is important for setting the exact z-value of the nozzle. The distance between the nozzle and the printing bed or fabric should be small and the same for all tested samples. Therefore, the fabrics were measured in two ways, first with respect to the textile standard and second with respect to the adjusted standard: the fabrics were measured when mounted in the frame specially designed for 3D printing. If, by mistake, the z-value of the nozzle was slightly different as planned, the value of the adhesive force was changed significantly, which shows how important it is to adjust the nozzle height accurately. 


\section{CONCLUSIONS}

The adhesion of the 3D printed objects to textiles is influenced by many factors: preparing of a 3D model for printing, setting up the printer, placing the fabric on the printing table and of course the construction parameters of the fabric. The results obtained show that any change affects the adhesion.

In general, we have found that the density of the fabric has the greatest influence on the adhesion force. If we observe the differences between the weaves, we find that the highest adhesion was achieved with a broken twill $1 / 3$ at the preset weft density of 15 threads/cm. In further research it is therefore important to determine the maximum adhesion force of 3D printed objects on textiles suitable for protective clothing.

\section{ACKNOWLEDGMENTS}

This work was founded by the Slovenian Research Agency, Slovenia (Infrastructural Centre RIC UL-NTF).

\section{REFERENCES}

[1] Awaya, F., Gilbert, M., Kelly, G., Fox, B., Pigram, P. J.: "Adhesion of Polymers", Progress in Polymer Science 34 (9), 948-968, 2009. doi: 10.1016/j.progpolymsci.2009.04.007.

[2] Gibson, I., Rosen, D., Stucker, B.: “Additive Manufacturing Technologies, 3D Printing, Rapid Prototyping, and Direct Digital Manufacturing" (Springer, New York NY, 2015.), pages 1-18.

[3] Jahan, I.: "Effect of Fabric Structure on the Mechanical Properties of Woven Fabrics", Advance Research in Textile Engineering 2 (2), 1018, 2017. doi: 10.26420/advrestexteng.2017.1018.

[4] Kozior, T., Blachowicz, T., Ehrman, A.; "Adhesion of three-dimensional printing on textile fabrics: Inspiration from and for other research areas", Journal of Engineered Fibers and Fabrics 15 (1-6), 2020. doi: 10.1177/1558925020910875.

[5] Kozior, T., Döpke, C., Grimmelsmann, N., Juhász Junger, I., Ehrmann, A.: "Influence of fabric pretreatment on adhesion of three-dimensional printed material on textile substrates", Advances in Mechanical Engineering 10 (8), 1-8, 2018. doi: 10.1177/1687814018792316.

[6] Malengier, B., Hertleer, C., Cardon, L., Van Langenhove, L.: "3D printing on Textiles: Testing of Adhesion", Proccedings of the International Conference on Intelligent Textiles and Mass Customisation, 2017, (ITMC2017: Ghent, Belgium, 2017).

[7] Melnikova, R. Ehrmann, A. Finsterbusch, K.: "3D printing of textile-based structures by Fused Deposition Modelling (FDM) with different polymer materials", Procedings of the Global Conference on Polymer and Composite Materials (PCM: Xi'an, China, 2014).

[8] Mpofu, N. S., Mwasiagi, J. I., Nkiwane, L. C., Njuguna, D.: "Use of regression to study the effect of fabric parameters on the adhesion of 3D printed PLA polymer onto woven fabrics", Fashion and Textiles 6, 2019. doi:10.1186/s40691-019-0180-6.

[9] Muck, D., Križanivskij, I.: “3D tisk", (Pasadena, Ljubljana, Slovenia, 2015.), pages 80-82.

[10] Pei, E., Shen, J., Watling, J.: "Direct 3D printing of polymers onto textiles: experimental studies and applications", Rapid Prototyping Journal 21 (5), 556-571, 2015. doi: 10.1108/RPJ-09-2014-0126.

[11] Rivera, M. L., Moukperian, M., Ashbrook, D., Mankoff, J., Hudson, S. E.: "Stretching the bounds of 3D printing with embedded textiles", Proceedings of the $2017 \mathrm{CHI}$ conference on human factors in computing systems 2017, (CHI'17: Denver, Colorado, 2017), pages 497-508.

[12] Sabantina, L., Kinzel, F., Ehrmann, A., Finsterbusch, K.: "Combining 3D printed forms with textile structures - mechanical and geometrical properties of multi-material systems", Procedings of the Global Conference on Polymer and Composite Materials, Materials Science and Engineering 2015, (PCM: Xi'an, China, 2015), page 87.

[13] Sanatgar, R. H., Campagne, C., Nierstrasz, V.: "Investigation of the adhesion properties of direct 3D printing of polymers and nanocomposites on textiles: Effect of FDM printing process parameters", Applied Surface Science, pages 403, 551-563, 2017. doi:10.1016/j.apsusc.2017.01.112.

[14] Sitotaw, D. B., Ahrendt, D., Kyosev, Y., Kabish, A. K.: "Additive Manufacturing and Textiles-State-ofthe-Art", Applied Sciences 10 (15), 2020. doi:10.3390/app10155033. 
[15] Spahiu, T., Al-Arabiyat, M., Martens, Y., Ehrmann, A., Piperi, E., Shehi, E.: “Adhesion of 3D printing polymers on textile fabrics for garment production", IOP Conference Series: Materials Science and Engineering, Aegean International Textile and Advanced Engineering Conference 2018, (Levos, Greece, 2018), page 459.

[16] Spahiu, T., Grimmelsmann, N., Ehrmann, A., Piperi, E., Shehi, E.: "Effect of 3D printing on textile fabric", Proceedings of the 1st International Conference Engineering and Entrepreneurship, (ICEE: Tirana, Albania, 2017)

[17] Spahiu, T., Piperi, E., Ehrman, A., Shehi, E., Rama, D.: "3D Printed Geometries on Textile Fabric for Garment Production", Proceedings of International Conference of Progress in Digital and Physical Manufacturing, (ProDPM 2019: Leiria, Portugal, 2019), pages 271-276. doi: 10.1007/978-3-03029041-2_34.

[18] Unger, L., Scheideler, M., Meyer, P., Harland, J., Görzen, A., Wortman, M., Dreyer, A., Ehrmann, A.: "Increasing Adhesion of 3D printing on textile fabrics by polymer coating", Tekstilec 61 (4), 265-271, 2018. doi:10.14502/Tekstilec2018.61.265-271.

(c) (1)

(C) 2020 Authors. Published by the University of Novi Sad, Faculty of Technical Sciences, Department of Graphic Engineering and Design. This article is an open access article distributed under the terms and conditions of the Creative Commons Attribution license 3.0 Serbia (http://creativecommons.org/licenses/by/3.0/rs/). 